\title{
Benchmarking Formula One auto racing circuits: A two stage DEA approach
}

\author{
Ester Gutiérrez*and Sebastián Lozano \\ Dpto. Organización Industrial y Gestión de Empresas I \\ Escuela Superior de Ingenieros, University of Seville \\ Camino de los Descubrimientos, s/n, 41092 Seville, Spain
}

ARTÍCULO PUBLICADO EN LA REVISTA

Operational Research (2019)

doi: https://doi.org/10.1007/s12351-018-0416-z

\begin{abstract}
Formula One (F1) World Championship has become one of the most successful sport tournaments over the last decade. Races take place in modern-day closed racing circuits, whose design plays a key role in racing results. This paper proposes a framework for the design efficiency assessment of the more representative racing circuits that hosted Grands Prix during the recent F1 seasons. The proposed approach considers two basic circuit features (namely, circuit length and number of turns) and combines car performance and race safety data. The methodology used is based on Data Envelopment Analysis (DEA). The number of inefficient circuits is small, five in the case of variable returns to scale and nine (out of 21) when constant returns to scale are assumed. Potential improvements in terms of speed, fuel consumption and safety targets are computed. For each inefficient circuit its reference set is identified. Also, a second-stage DEA fractional regression analysis is carried out to study the influence of the circuit type (race or street circuit), the track orientation (clockwise or anticlockwise) and the number of redflagged races due to rainfall on the circuits' efficiency. The results indicate that all three variables are significant. The implications of the results for track designers and F1 organizers are also discussed.
\end{abstract}

Keywords: Formula One race circuits; design efficiency; Data Envelopment Analysis; SBM; fractional regression analysis

* Corresponding author:

E-mail: $\quad$ egm@us.es

Phone: +34-954486198

Fax: $\quad+34-954487329$ 


\section{Benchmarking Formula One auto racing circuits: A two stage DEA approach}

\section{Introduction}

Formula One (F1) has gained significant global recognition in the last decades. F1 auto races are considered mega sporting events offering a large positive impact for host cities across different dimensions, such as branding for tourism destination, social-cultural impact and impact on the local economy (Cheng and Jarvis, 2010). The mass media have had a leading contribution to its increasing expansion worldwide (Henry et al., 2007). Thus, for example, in terms of audience, the F1 series captured 390 million viewers worldwide in 185 countries in the 2016 season (FOM, 2017).

The F1 season comprises a series of outdoors city-to-city races, known as Grands Prix, that take place annually from to March to November. The results of each race provide a rankingboth for the drivers and the car constructors. The racing position of every F1 driver/constructor depends on a number of important factors such as quality of the cars (including engine and aerodynamic performance, brakes, etc.), characteristics of the race track, talent of racing drivers, effectiveness of race strategies and others (weather conditions, tyre performance, etc.).

In particular, the F1 circuit layout is considered to be one of the most important components of the race competition. Closed-circuit racing tracks are licensed by the FIA (FédérationInternationale de l'Automobile) according to the style of track and the classes of cars to be raced on them. Currently, the FIA's rules on circuit design are harsh, looking at the improvement in the caroperation safety as much as the car performance.

The success of the F1 World Championship as the highest auto racing tournament class derives from the performance of the drivers, constructors and the F1 race circuits. The F1 world has attracted a significant amount of attention from academics in recent years due to its highly competitive environment, partially induced by the openness to new urban environments (Lefebvre andRoult, 2011). These studies analyse various F1 issues, such as, F1 car designs and failure analysis (Jenkins and Floyd, 2001; 
PerantoniandLimebeer, 2014; Savage, 2010), car drivers' injuries (MinoyamaandTsuchida, 2004), practices of intellectual capital (SolitanderandSolitander, 2010), estimation of the effect of aging on productivity (Castellucci et al., 2011), public relations strategies (Pfahland Bates, 2008), brand profiles (Rosenberger andDonahay 2008), stakeholder theory (Xue and Mason, 2011), social-cultural impacts (Cheng and Jarvis, 2010; Fairley et al., 2011; Jago et al., 2003; Liu and Gratton, 2010), etc. Although, the references cited above encompass many F1 features, contributions regarding F1 circuits are still scarce. Two exceptions are studies by Casanova et al. (2001), who propose two methods for the reconstruction of Barcelona (Spain) and Suzuka (Japan) F1 circuits based on race car speed and lateral acceleration, and Lefebvre andRoult (2011), who analyse F1 circuits' expansion in the last decades.

More research has been carried out as regards performance analysis in F1: Kladroba (2000) focuses on ordinal multicriteria methods and illustrates the case of the $1998 \mathrm{~F} 1$ drivers' world championship; the contribution of Gomes Junior and Soares de Mello (2007) and Chaves et al. (2010) assess2007 F1 world drivers' championship usingthe ELECTRE II multicriteria decision making method;Sitarz (2013) proposes a system of points for rankings in sports, presenting as an example the $2011 \mathrm{~F} 1$ championship;Phillips (2014) compares F1 driver performances during 1950-2013 using a statistical model, providing lap-time data predictions; Anderson (2014) applies three statistical models, two based on paired-comparison and one based on the rankordered logit function, to rank F1 driver performance in the 2012 season;Soares de Mello et al. (2015) present an adaptationof the Condorcet method in a weakly rational decision maker environment to establish the ranking of the F1 constructors in the 2013 championship; more recently, Bell et al. (2016) propose across-classified multilevel model to evaluate the F1 Driver and Constructor performance across the period 19502014.

There have, however, been fewer studies using a deterministic frontier analysis approach, such as Data Envelopment Analysis (DEA), to assess F1 performance, despite its wide use in many other sports,such as football (e.g. Espitia-EscuerandGarcíaCebrián, 2010; Villa and Lozano 2016), basketball (e.g. Chen et al., 2017; Moreno and Lozano, 2014), baseball (e.g. Lewis et al., 2009), cricket (Amin and Sharma. 2014), 
Olympic games (e.g. Lozano et al., 2002; Wu et al., 2010), sport federations (de Carlos et al., 2017), tennis (e.g. Klaasenand Magnus, 2009; Ruiz et al., 2013), etc. To the best of our knowledge, there are only two F1 DEA studies in the literature: Gomes Junior and Soares de Mello (2007) that assesses F1 world drivers' championship using DEA (F1 season 2006), and Gutiérrez and Lozano (2014), that analyses F1 teams' performance (using Principal Component Analysis-based variable selection and DEA) over a number of F1 seasons up to 2011.

The proposed approach is related to those DEA applications in which different products are benchmarked. Thus, DEA has been used to compare printers (Doyle and Green 1991), car models (e.g. Hwang et al., 2013; Papahristodoulou, 1997), industrial robots (e.g. Braglia and Petroni, 1999), computer programs (Herrero and Salmerón, 2005), facility layouts (e.g. Ertay et al., 2006), etc. In our case, the entities to be benchmarked are F1 circuits. The attributes considered are basically three: speed, safety and environmental impact. Speed is considered because F1 events are, mainly and above all, races and speed is the key element in a race. Safety, for both the drivers and the public, is clearly also a main concern. Finally, although the duration and frequency of F1 events are limited, that is no reason for ignoring the fact that some F1 races may generate more pollution than others. The main environmental impact considered has been $\mathrm{CO}_{2}$ emissions, which can be considered to be proportional to fuel consumption (Demir et al., 2014).

The idea behind the proposed approach for F1 circuits benchmarking is to estimate, in a non-parametric way, the relationship (i.e. the so-called production function) between key circuit design features and main circuit performance measures. This allows not only assessing the efficiency of the circuits overall, along with the speed, environmental and safety dimensions, but also, by regressing the efficiency scores obtained with some explanatory variables, the effects of these exogenous factors can be tested and estimated. In particular, it has been found that race tracks are more efficient than street racing circuits, thatanticlockwise-oriented circuits are less efficient than clockwiseoriented circuits and that circuits in rainy weather regions are less efficient than circuits in dry weather regions. 
As regards the methodology used, first of all, the proposed DEA approach allows the identification of the efficient circuits, i.e. those with a superior design in terms of speed, fuel efficiency and safety. For those circuits that are found to be inefficient, their shortfalls in each of these dimensions have been assessed. The reference set (i.e. peer group) of each inefficient circuit, i.e. those efficient circuits that may act as benchmarks for improvement, are also reported. Also, fractional regression models are used for the second stage of the DEA model. The regression model analysishas been carried out to describe the association between the DEA efficiency scores and relevant characteristics of F1 circuits, i.e. the type of circuit (race or street), the track direction(clockwise or anticlockwise) and the number of red-flagged races due to rain (in the last five races). The selection of this specific methodology of the two stage regression model is based on the fractional nature of the DEA efficiency scores and overcomes several highly restrictive assumptions of linear and censored regression models.

Summarising, the efficiency of a racing circuit is a key issue in the F1 competition since the overall success of the F1 series depends on the performance of its races. This paper analyses the relative efficiency of the race circuits that host the F1 competition, both in terms of cars' performance (i.e. speed and fuel efficiency) and circuit safety. The remainder of the paper is organized as follows. Section 2 describes the proposed approach. Section 3 presents the results. The proposed approach and implications of the study are further discussed in Section 4. Finally, in Section 5 the main conclusions are drawn and further research outlined.

\section{Proposed approach}

\subsection{First stage: DEA model}

DEA is a non-parametric mathematical tool for assessing the relative efficiency of a number of comparable entities. The entities to be benchmarked can represent factories, countries, departments, industry sectors, football teams, tennis players, etc. and are usually designated as Decision Making Units (DMUs). All DMUs consume inputs in order to produce outputs. From the set of observations, the Production Possibility Set (also called the technology) is inferred using some basic assumptions such as 
envelopment, free disposability, convexity or scalability (e.g. Cooper et al., 2006). Considering or not the latter assumption leads to the two most common technologies, which are labelled, respectively, Constant Returns to Scale (CRS) (e.g. Charnes et al., 1978) and Variable Returns to Scale (VRS) (e.g. Banker et al., 1984) technologies.

Given the technology, DEA models aim to project the DMUs onto the efficient frontier, which corresponds to the best practice. Thus, DMUs for which no potential improvement is feasible are deemed relatively efficient and therefore belong to the efficient frontier. In contrast, those DMUs for which a reduction in input consumption and/or an increase in output production are considered feasible are assessed as inefficient and an efficiency score is computed. The efficiency score measures the distance to the frontier and depends on the estimated amount of potential input reductions and output increases. There are different DEA models depending on the technology, the projection direction and the metric used to compute the relative efficiency (Cooper et al.,2004).

A crucial step in DEA modelling is the selection of the input and output variables as everything that follows depends on that selection. As Cook et al. (2014) indicate, the selection of the inputs and outputs is not always discussed, given the importance it has, and also the selection of the proper inputs and outputs of a DEA study generally depend on the aims of the study and on the nature of the DMUs being analysed.There are a number of variables that can, in principle, be considered for an F1 DEA application. Thus, one can say that the elevation change along the circuit or the longest straight may have an effect. The run-off area available may also be a variable of interest, as it can affect the drivers' safety (Perantoni and Limebeer, 2014). Other factors that can affect the cars' performance are the altitude of the location and the weather conditions (temperature, or rain, for example) (Judde et al., 2013; Wloch and Bentley, 2004). It is difficult, however, to include the weather conditions because they are not constant for a given circuit, i.e. the temperature or the occurrence of rain is different from one season to the next, and it can be argued that these uncontrollable variables are not strictly speaking circuit design features. Regarding F1 design features, the FIA provides an updated list of requirements for the F1 circuit drawing (FIA, 2018) even providing an AUTOCAD template; in this regard, Casanova et al. (2001) develop the reconstruction of the Barcelona and Suzuka race circuits from racing car characteristics and Alnaser et 
al. (2007) highlight the success of the Bahrain International F1 circuit from its architectural characteristics.

After careful evaluation, the result was five main variables: two of them are key circuit design features (circuit length and number of turns) and the other three represent basic dimensions that we consider important for benchmarking F1 circuits (i.e. speed, safety and environmental impact). More specifically, as shown in Figure 1, fastest lap time (in seconds) (http: //www. fia.com) and fuel use per lap (in kilograms) (http: //f1facts.com \results) are considered as inputs. These variables correspond to speed and fuel consumption, the latter beinga surrogate for greenhouse gases emissions and their related environmental impact. On the output side, two types of variables can be distinguished: non-discretionary outputs related to track characteristics (namely, number of turns and lap length, in kilometres) (http://fia.com), and an undesirable output related to circuit safety (namely, number of car withdrawals per 100 laps due toaccidents and collisions) (http://en.espnf1.com). The inclusion of the number of accidents as a variable in the DEA model proposed in this paper is inspired by the permanent concerns of Formula One Management Ltd. (FOM), FIA and other F1 stakeholders regarding the issue of safety.

**************************Insert Figure 1 around here $* * * * * * * * * * * * * * * * * * * * * * *$

The reason for considering lap length and number of turns stems from the fact that these two circuit design features affect the race (Castelluci et al., 2011; Papachristos, 2014). The fastest lap is an input which measures the extent to which the design is aimed at speed. Of course, the duration of a lap depends on the circuit length (which is why that variable is included as an input).

Note that in order to make the DMUs homogeneous and comparable all the variables are measured per lap (100 laps in the case of accidents-caused withdrawals) and that the two non-discretionary variables considered (which represent the main physical/geometric attributes of the circuit) are of the internal type (Camanho et al., 2009) and, hence, follow the Banker and Morey (1986) approach. Alternative ways of modelling this type of internal non-discretionary variable, especially for the CRS case, are discussed in Camanho et al. (2009). In the end, the inputs and outputs selected imply 
that a circuit is inefficient if there exists some other circuit (with the same length or longer and with the same or a larger number of turns) that involve less time, less fuel consumption and fewer accidents.

As will be commented on in Section 3, one of the variables considered (namely, the number of accidents/100 laps) refers to a certain timespan (1998-2014). Since we are very interested in considering the safety dimension of circuit design, in order to include the number of accidents that have occurred we have to consider several years because, fortunately, accidents do not occur too frequently. However, in this period some circuits have hosted more races than others. That is why the (undesirable) output is not the absolute number of accidents but it is normalized by considering how many accidents occur in every 100 laps. Thus, circuits that have held more races can be compared with circuits that have held fewer and also the benchmarking is fair because in this way this output variable refers to an intrinsic feature of the circuit design (the lap, or in the case of this variable, 100 laps).

The specific DEA model used is a weighted Slacks-Based Measureof efficiency (SBM), (Tone, 2001) DEA model, which is a common approach when some outputs are undesirable (e.g. Lozano and Gutiérrez 2011). There are different ways of modelling undesirable outputs in DEA (e.g. Färe and Grosskopf, 2003; Scheel, 2001; Seiford and Zhu, 2002). One of them is to consider the undesirable outputas weakly disposable, i.e. efficient DMUs can only reduce the undesirable output if they also reduce the desirable outputs. In particular, in the proposed approach, the weak disposability of the undesirable output is modelled using the approach in Kuosmanen (2005). Alternatively, the approach in Färe and Grosskopf (2003), which does not use separate abatement factors for the different DMUs, can be used.

In addition to the chosen SBM approach, let us recall that there are severalother types of DEA models that can handle undesirable outputs, such as the Directional Distance Function (DDF) model (e.g. FäreandGrosskopf, 2003; Lozano et al., 2013) and the Slacks-Based Inefficiency (SBI) model (e.g. Fukuyama and Weber, 2010; Lozano, 2016). Each of them has its pros and cons. A disadvantage of DDF models is that input and desirable output slacks may remain. This does not happen in SBM or SBI. DDF has the advantage of using a directional vector, which allows computing the distance to the 
frontier in several directions. Note that we are referring to the conventional case thatassumes that the directional vector is exogenously given and not to those DDF approaches that endogenously compute the directional vector (see Wang et al., 2017), neither to the so-called reversed DDF approach (Pastor et al., 2016)nor to the non-radial DDF model (e.g. Ferreira and Marques 2016).Although SBI also uses a direction vector, its role is more of a normalizing nature rather than defining the projection direction (Pastor andAparicio, 2010). What can be used in SBM as a surrogate of the direction vector are the weights used in the objective function. These weights are assumed to be normalized, i.e. their sum is unity.

In order to formulate the mathematical model, let

$\underline{\text { Data }}$

$$
\begin{array}{ll}
I=\{1,2\} & \text { set of inputs } \\
i \in I & \text { index on inputs } \\
w_{i} & \text { relative weight of improving input } \mathrm{i} \in \mathrm{I} \\
0 & \text { index of DMU being projected } \\
K=\{1,2\} & \text { set of non-discretionary outputs } \\
k \in K & \text { index on non-discretionary outputs } \\
B=\{1\} & \text { index on undesirable outputs } \\
b \in B & \text { relative weight of improving undesirable output } \mathrm{b} \in \mathrm{B} \\
\hat{w}_{b} & \text { set of DMUs } \\
J=\{1,2, \ldots, n\} & \text { index on DMUs } \\
j \in J & \text { amount of input i } \in \text { I consumed by DMU } \mathrm{j} \in \mathrm{J} \\
z_{b j} & \text { amount of non-discretionary output } \mathrm{k} \in \mathrm{K} \text { produced by } \mathrm{DMU} \mathrm{j} \in \mathrm{J} \\
x_{k j} &
\end{array}
$$




\section{$\underline{\text { Variables }}$}
$\lambda_{j}, \mu_{j}$
multiplier variable used to compute the target inputs and outputs of DMU 0
$s_{i} \quad$ improvement (i.e. slack) of input $\mathrm{i}$
$\hat{s}_{b} \quad$ improvement (i.e. slack) of undesirable output b

The proposed VRS SBM DEA model is thus,

$$
\theta=\operatorname{Min} 1-\sum_{i \in I} w_{i} \frac{s_{i}}{x_{i 0}}-\sum_{b \in B} \hat{w}_{b} \frac{\hat{s}_{b}}{z_{b 0}}
$$

s.t.

$$
\begin{aligned}
& \sum_{j}\left(\lambda_{j}+\mu_{j}\right) \cdot x_{i j}=x_{i 0}-s_{i} \quad \forall i \\
& \sum_{j} \lambda_{j} y_{k j} \geq y_{k 0} \quad \forall k
\end{aligned}
$$

$$
\sum_{j} \lambda_{j} z_{b j}=z_{b 0}-\hat{s}_{b} \quad \forall b
$$

$$
\begin{aligned}
& \sum_{j}\left(\lambda_{j}+\mu_{j}\right)=1 \\
& \lambda_{j}, \mu_{j} \geq 0 \quad \forall j \quad s_{i} \geq 0 \quad \forall i \quad \hat{s}_{b} \geq 0 \quad \forall b
\end{aligned}
$$

This linear programming model computes a target operating point within the production possibility corresponding to assuming VRS, non-discretionary desirable outputs and weak disposability of the undesirable outputs. The objective function provides a weighted SBM efficiency score. This type of non-radial, non-oriented DEA model has the indication property (i.e. the efficiency score is unity if and only if the DMU is 
efficient), apart from other properties directly inherited from using SBM efficiency, namelyunits invariance, monotonicity and reference-set dependence(see Tone, 2001).

Note that the above DEA model tries to simultaneously decrease the inputs (e.g. the fastest lap time) and the undesirable output, i.e. to increase speed and safety at the same time. This may seem contradictory and actually it is not possible if the DMU is efficient. However, the optimization model sees if there is an operating point in which that occurs and tries to maximize the weighted improvements in both the inputs and the undesirable output.

A subtler issue is the interpretation of reducing the undesirable outputs when, as in our case, the desirable outputs are non-discretionary. That a certain variable is nondiscretionary means that its value cannot be changed. But that refers to a specific DMU, the one that is being assessed. However, when projecting that DMU,DEA considers the whole production possibility set, which includes all virtual operating points whose input-output mixesare theoretically possible. It is when searching among those feasible operating points that it makes sense to allow for a reduction of an undesirable output compatible with possible increases of the desirable outputs, even if those outputs are non-discretionary. That is, of course, provided that the technology (i.e. the production possibility set) considers such operating point feasible. In other words, when computing the target,the proposed DEA model does not consider a fixed operating point (whose non-discretionary outputs could not be changed) but it has freedom (within the production possibility set) to choose any operating point with its corresponding input and output variables (including the non-discretionary).

The computed DEA projection provides targets which imply potential improvements whose interpretation is the following. Given the length and number of turns of the circuit, and based on the observed dataset, it would be feasible to reduce (in the amount given by the respective slacks) the observed fastest lap time, the observed fuel consumption and the observed number of accident-caused withdrawals. In other words, for that length and number of turns, the design of the circuit is not as speedy, nor as fuel-efficient nor as safe as it could be according to the production possibility set inferred from the given observations. 
For each inefficient circuit, looking at the optimal values of the $\lambda_{j}$ variables, its corresponding reference set can be identified. This information is useful to identify, for each inefficient DMU, which circuits to consider as benchmarks.

Although the above models assume VRS, without much effort (just deleting the convexity constraint $\left.\sum_{j}\left(\lambda_{j}+\mu_{j}\right)=1\right)$ a CRS efficiency score can be obtained. The CRS analysis, which corresponds to ignoring the possible scale size effects in the design of the circuits, always produces lower efficiency scores and a lower number of efficient DMUs.

Another interesting possibility is to estimate the maximum possible improvement along each of the three improvable dimensions. That can be done using a specific weight vector that assigns a weight of 1.0 to that dimension and 0.0 to the rest. Thus, considering a weight vector $w_{1}=1, w_{2}=\hat{w}_{1}=0$ a speed efficiency score efficiency score $\theta_{0}^{\text {speed }}$ can be obtained. Similarly, using $w_{2}=1, w_{1}=\hat{w}_{1}=0$ and $w_{1}=w_{2}=0, \hat{w}_{1}=1$ a fuel efficiency score $\theta_{0}^{\text {fuel }}$ and a safety efficiency score $\theta_{0}^{\text {safety }}$, respectively, can be computed.

Finally, in order to check for the presence of outliers in the data the method in Anh Tran et al. (2010) was applied and it was found that all the efficient DMUs had small $\lambda$-count and $\lambda$-sum indexes. When outliers were present a robust frontier method (e.g. Ferreira et al. 2018, Ferreira and Marques 2018) can be applied.

\subsection{Second stage: Regression models}

In order to study the impact of factors that can influence efficiency, a second stage analysis is performed regressing the efficiency scores on some contextual variables.In the scientific literature about second stage DEA efficiency analysis, several regression models have been considered. Standard linear models based on ordinary the least squares estimation procedure offer best linear unbiased estimates upon statistical distributional assumptions and biased estimates when the assumptions do not hold. In 
general, linear regression models are not suitable for second stage efficiency analysis because the estimates may lie outside the closed unit interval. Truncated and censored regression models based on the maximum likelihood estimates have been used to take into account the bounded nature of the efficiency score as response variable; however, those models are actually mis-specified when modelling efficiency DEA scores and are not exempted from distributional assumptions (Hoff, 2007; Simar and Wilson, 2008; McDonald, 2009; Ramalho et al., 2010). A semi-parametric bootstrapped regression model was proposed by Simar and Wilson(2008) to make inferential statements.In this study, the frontier is considered as an observed best-practice concept, hence DEA efficiency scores are treated as observed measures of technical efficiency (McDonald, 2009; Ramalho et al., 2010). Several statistical regression models are considered. A linear conditional mean model could be used to describe the DEA efficiency scores $(E F F)$ :

$$
E\left(E F F_{i} \mid \mathbf{x}_{i}\right)=\mathbf{x}_{i} \boldsymbol{\beta}, i=1,2, \ldots, n
$$

$\boldsymbol{x}_{\boldsymbol{i}}$ denotes the $k$-dimensional vector of the variables of the $i$-th DMU observation and $\boldsymbol{\beta}$ a $k$-dimensional vector of unknown parameters. However, the DEA efficiency is not generated from a truncated process but rather is the outcome of a fractional process (McDonald, 2009).

$$
E\left(\left.E F F\right|_{i} \mathbf{x}_{i}\right)=H\left(\mathbf{x}_{i} \boldsymbol{\beta}\right), i=1,2, \ldots, n
$$

where $H(\cdot) \in[0,1]$ is a nonlinear function, and may adopt a logit (2.a), probit (2.b), log$\log (2 . c)$ or complementary log-log (2.d) specification.

$$
\begin{gathered}
H_{\text {logit }}\left(\mathbf{x}_{i} \boldsymbol{\beta}\right)=\frac{\exp \left(\mathbf{x}_{\mathbf{i}} \boldsymbol{\beta}\right)}{\left(1+\exp \left(\mathbf{x}_{\mathbf{i}} \boldsymbol{\beta}\right)\right)} \\
H_{\text {probit }}\left(\mathbf{x}_{i} \boldsymbol{\beta}\right)=\Phi\left(\mathbf{x}_{i} \boldsymbol{\beta}\right) \\
H_{\text {loglog }}\left(\mathbf{x}_{i} \boldsymbol{\beta}\right)=\exp \left(-\exp ^{\left(-\mathbf{x}_{i} \boldsymbol{\beta}\right)}\right)
\end{gathered}
$$




$$
H_{c l o g l o g}\left(\mathbf{x}_{i} \boldsymbol{\beta}\right)=1-\exp \left(-\exp ^{\left(\mathbf{x}_{i} \boldsymbol{\beta}\right)}\right)
$$

One-part standard fractional regression models are statistically suitable for conducting this type of fractional regression analysis based on the following fundamentals: a) no underlying assumption is required about the conditional distribution of DEA efficiency scores or heteroskedasticity patterns; b) the specification of the model can adopt the asymmetric character of the efficiency scores; c) the estimates can be computed by quasi-maximum likelihood. In addition, fractional models proportion better performance results than other regression models when efficiency DEA scores are concentrated at unity (Papke and Wooldridge, 1996; Ramalho et al., 2010).

In order to examine the link specification for the conditional mean of efficiency scores the Ramsey RESET test (Ramsey Regression Equation Specification Error Test) is tested and uses the null hypothesis $E\left(E F F \mid \mathbf{x}_{i}\right)=H\left(\mathbf{x}_{i} \boldsymbol{\beta}\right)$ and the alternative hypothesis $E\left(E F F \mid \mathbf{x}_{i}, \mathbf{z}\right)=H\left(\mathbf{x}_{i} \boldsymbol{\beta}+\mathbf{z} \boldsymbol{\gamma}\right)$, where $\boldsymbol{\gamma} \neq \mathbf{0}$ and $\mathbf{z}=\left[(\mathbf{x} \hat{\boldsymbol{\beta}})^{2},(\mathbf{x} \hat{\boldsymbol{\beta}})^{3}, \ldots,(\mathbf{x} \hat{\boldsymbol{\beta}})^{J+1}\right]$ allow using a higher-order polynomial regression specification (for further details see Ramsey, 1969).

\section{Assessment of F1 racing circuits' efficiency}

This section discusses the dataset used and the results obtained from the DEA analysis.

\subsection{Dataset}

The circuits considered in the analysis, their main features and corresponding descriptive statistics are listed in Table 1. The dataset comprises 21 circuits, selected on the basis of the availability of as many DMUsas possible through the $17 \mathrm{~F} 1$ seasons 1998-2014. New regulations related to engines, cars, penalties and testing have taken place since then, producing a gap in the times series. Table 1 also shows the main data sources. Whenever possible, the collected data were double-checked against other F1related sources. 
The database includes all the circuits that hosted 2014 F1 races (except for Sochi Autodrom, Russia, that joined the F1 World Championship in 2014) plus three other circuits, namely Korea International Circuit (South Korea), Istanbul Park (Turkey) and Buddh International Circuit (India), that have regularly hosted F1 World Championship in the latest seasons. The track design of each of the circuits considered is considerably different (FIA, 2017). Thus, for example, Silverstone (U.K.) is a generally fast circuit with some slow corners and several fast wide turns, while Shanghai International circuit (China) features medium-speed corners and a straight that is flat out for almost 1.2 kilometres.

**************************Insert Table 1 around here************************

The number of seasons in which a Grand Prix was held in a circuit and the number of car withdrawals/100 laps exhibit significant variability among the circuits. In this regard, the withdrawals data used consist of the number of recorded car withdrawals from the race per 100 laps, excluding technical problems (e.g., gearbox, engines, broken wing). Table 2 lists the number of registered car withdrawals due to accidents and collisions occurring in each F1 season from 1998 through to 2014. From 1998 to 2009, the number of these F1 circuits' car withdrawals represents over $60 \%$ of the total for the 1998-2014 period, while the accumulated number during the 2010-2014 period represents around $40 \%$.

*************************Insert Table 2 around here************************

Note that although the dataset considered includes up to the 2014 season, this does not mean, that, for example, the fastest lap input refers to the fastest lap that year. Actually, it refers to the fastest lap recorded in the history of the circuit up to 2014. Analogously, as indicated above, the number of accidents refers to the period 1998-2004. Fuel use figures are estimations and refer to the 2014 season. Although there may be some inconsistency, in that the variables do not refer to the same time interval that should not be a problem, provided that the same intervals are used for all DMUs. In particular, given the lumpy and infrequent character of accidents it has been deemed preferable to accumulate them for as long a period as possible, which is equivalent to averaging them. 
In order to obtain an idea about the data distribution,Figures 2 and 3 show the boxplots of the five input and output variables considered and their corresponding scatterplots, respectively. In addition, Figure 3 shows the correlation coefficient between each input and output variable. Note that the variables where there is more variability are the fastest lap and the number of turns. There is positive correlation between fastest lap and fuel use/lap, i.e. as a lap takes longer then more fuel is consumed. There are also positive correlations between fastest lap and lap length and number of turns, indicating that if the circuit length is of great length or has many turns then a lap takes longer. Fuel use/lap is positive correlated with lap length and, to a small extent, with the number of turns. The number of turns and the circuit length are only slightly positively correlated. The correlation of the number of accidents/100 laps with the fastest lap and fuel use is negative but very small. One would expect the number of accidents/lap (or per 100 laps) to depend on the average speed but the two inputs (fastest lap and fuel use/lap) are related to the average speed but mediated by the circuit length. Thus, for example, the fastest lap corresponds to the lap length divided by the average speed. Similarly, the fuel consumption grows with the average speed but also with the lap length. The correlation of the number of accidents/100 laps with the number of turns is slightly negative and with the lap length is positive, although small.

************************Insert Figure 2 around here $* * * * * * * * * * * * * * * * * * * * * * *$

*************************Insert Figure 3 around here $* * * * * * * * * * * * * * * * * * * * * * *$

\subsection{Efficiency scores}

The proposed SBM DEA model has been solved for both VRS and CRS using uniform weights $w_{1}=w_{2}=\hat{w}_{1}=1 / 3$. Table 3 shows the corresponding efficiency scores as well as the potential improvements (of the discretionary variables) corresponding to the target operating points computed by the VRS DEA model. Only five circuits are found to be technically inefficient by the VRS analysis. The CRS efficiency scores are lower andassess more circuits (up to nine) as inefficient. The potential improvements estimated are rather modest (i.e. even the inefficient circuits are not far from efficiency) 
except in the case of circuit $\mathrm{C} 19$, for which significant improvements are deemed possible.

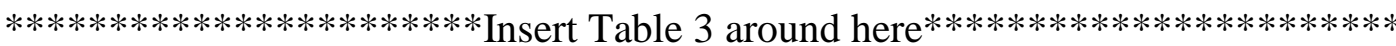

Table 4 shows, for the five technically inefficient circuits, their reference set and corresponding optimal values of $\lambda_{j}$ and $\mu_{j}$ variables. The reference set represents the subset of efficient DMUs from which the target efficient operating point is computed (using the optimal values of the $\lambda_{j}$ and $\mu_{j}$ variables as coefficients of the corresponding convex linear combination). Note that the $\mu_{j}$ variables are always zero and that each inefficient circuit has a different reference set. In some cases, as in the cases of C3, C15 and C19 there is a main benchmark (whose corresponding $\lambda_{j}$ is close to unity) and thus represents the specific efficient circuit that should be taken as the basic reference. In the cases of $\mathrm{C} 5$ and $\mathrm{C} 21$, however, there is no a single main benchmark but several. Note that among the different efficient circuits the ones with a higher peer count (i.e. that intervene in the reference set of more inefficient DMUs) are C10, C16 and C20. Note also that there are several efficient circuits (namely C1, C4, $\mathrm{C} 8, \mathrm{C} 13, \mathrm{C} 14, \mathrm{C} 17$ and $\mathrm{C} 18)$ that do not belong to any of the reference sets of the inefficient circuits.

*************************) Insert Table 4 around here $* * * * * * * * * * * * * * * * * * * * * * *$

Figure 4 shows the variable-specific efficiency scores along the speed, fuel consumption and safety dimensions. The average value for each dimension is also shown so that the circuits with efficiency scores above or below the average can be identified. Note that the VRS efficient DMUs are efficient in all these three specific dimensions. Note also that Aver. $\theta^{\text {speed }}=0.992>$ Aver. $\theta^{\text {fuel }}=0.974>$ Aver. $\theta^{\text {safety }}=0.939$. This means that safety is the dimension with the largest efficiency improvement potential, followed by fuel consumption. In contrast, the efficiency as regards speed is very high. The only circuit that seems to have some improvement potential in that dimension is C19 (Korea International circuit). 


\subsection{Second-stage analysis}

In a second stage, a regression analysis has been carried out to understand why F1 circuits differ in their efficiency scores and to investigate the effects of contextual variables. The variables considered in the models include twodesign-related variables, namely the type of circuit (i.e. street or race circuit) andthe track orientation (clockwise or anticlockwise), as well asa proxy climate variable, represented by the number of redflagged racesdue tounsafe track conditions caused by rainfallin the past five races. As shown in Table 1, the dataset includes four street circuits (namely, Albert Park, Monte Carlo, Gilles Villeneuve and Marina Bay) while the rest are race circuits. Similarly, from a track orientation perspective, a majority of the circuits has a clockwise orientation, with the exception of Marina Bay, José Carlos Pace, Yas Marina and Korea International. The hazard of unsafe track conditions caused by the rainfall is not a frequent event, except forSepang, Albert Park, Circuit of Catalunya,Suzuka and Korea International.

The corresponding fractional models were estimated using frm(Ramalho, 2017), an $\mathrm{R}$ package.The quasi-maximum likelihood estimation results of the fractional models for the different functional specifications, besides the Ordinary Least Squares (OLS) linear regression model estimation, are presented in Table 5.

The estimation results of the linear model and the fractional models differ significantly. In the OLS linear regression, the number of red-flagged races due to unsafe track conditions caused by rainfall is the only variable considered statistically significant and the percentage of efficiency variability explained by the linear model is $45.1 \%$ indicating a poor model fit. In addition, the $55 \%$ of the estimated efficiency scores in OLS linear model do not belong to $(0,1]$.

However, all four fractional regression models identify as statistically significant the three variables considered, with no disagreement between the sign of theireffects. The coefficient of the type of circuit is highly statistically significant, and negative, in all 
fractional models. This means the efficiency scores of street circuits and race circuits are different, i.e. that street circuits have better efficiency results than race circuits. As regards the red-flagged races due to the rain variable, the results indicate that it can significantly affect the track conditions and reduce the efficiency of F1 circuits, i.e. rain likelihood also has a negative effect on circuit efficiency. Clockwise orientation, on the other hand, affects the circuit efficiency score positively.Moreover, the fractional regressions models describe a better association between the observed model and the estimated model than the OLS linear model.

The RESET test, using second order $(J=1)$ and the Lagrange multiplier version, reveals that as fractional models specifications do not differ greatly, each of these could be chosen to perform second stage efficiency scores ( $p$-value Logit $=0.273 ; p$ value $_{\text {Probit }}=0.202 ; p$-value $\log -\log =0.279 ; p$-value clog-log $\left.=0.106\right)$.

**************************Insert Table 5 around here*************************

\section{Discussion}

From the selection of the input and output variables it can be seen that the proposed DEA approach corresponds to considering each circuit as an entity that consumes time and fuel to produce a lap that has a certain length, certain number of turns and a certain probability of accident. The latter is considered an undesirable output so that the smaller the better. As regards the other two outputs, they have been considered nondiscretionary because doing otherwise would imply that, ceteris paribus, a circuit would be more efficient if it is longer and has more turns, something which we do not mean. The proposed model considers that, ceteris paribus, a circuit is more efficient if it is faster, safer and less polluting. Also, the non-discretionary character of the length and number of turns outputs implies that we are not considering the possibility of remodelling the circuit, i.e. we are benchmarking the current circuit designs.

An interesting question, posed by one of the reviewers, is that some of the variables used for benchmarking the circuits (such as speed or fuel consumption) are more dependent on drivers and constructors than on the circuits themselves. Thus, while some of the variables (i.e. number of turns and circuit length) completely fall under the 
responsibility of the circuits, others (such as the fastest lap, the fuel consumption or the number of accidents) also depend on the drivers and constructors. However, provided that the drivers and constructors are the same in all the races, the differences in fuel consumption, fastest laps and accidents between the different circuits can be attributed to the circuits themselves. Therefore, considering those variables for circuit benchmarking is a reasonable assumption that, admittedly, ignores that actually the drivers vary over time and sometimes even within a season or that the cars suffer modifications and improvements between seasons and even between races.

Since the different stakeholders have differing (and sometimes even conflicting) aims, a different DEA model may result depending on the perspective adopted. The perspective adopted in this paper is that of the public in general and auto racing fans in particular. It is assumed that they are interested in three main aspects: speed, safety and environment; hence the three discretionary variables that the DEA model tries to improve. However, that the model focuses on one stakeholder does not mean that other stakeholders may not also be interested in some of these aspects. The best example is safety, which is a concern probably shared by all stakeholders. Note also that the weighted nature of the proposed SBM model allows taking into account some preference structure among the three aims considered. In the paper we have reported the results for the equal weights case as well as for giving all the weight to each of the three aspects separately. Of course, the corresponding results only vary in the case of inefficient circuits, as for the efficient circuits the results are the same for any weighting.

About the results obtained, we have, on the one hand, the identification of the circuits that are inefficient, the assigning of an overall efficiency score, the quantification of their margin for improvement in each dimension and the reference DMUs they can use as benchmarks. On the other hand, from the second stage, it has been found that race tracks are more efficient than street racing circuits, that a clockwise orientation increases the efficiency of the circuits and that weather conditions (particularly, rain) negatively affect the circuit efficiency. These findings can be useful for track designers and F1 organizers. Thus, hosting races in street racing circuits should be avoided as they lead to more fuel consumption, more accidents and a lower average speed than an equivalent race track (with the same length and number of turns). Also, when designing the circuit it is preferable, ceteris paribus, to adopt a clockwise orientation as this leads 
to faster laps, less fuel consumption and increased safety. And, finally, when choosing a location for a race (or when scheduling the different Grands Prix of a season) it should be borne in mind that bad weather affects efficiency negatively byincreasing accidents and fuel consumption and reducing speed. Two of the above recommendations/effects are reasonable and to a certain extent unsurprising. The fact that they have been confirmed empirically is nevertheless interesting and supports the validity of the proposed approach. As regards the influencing effect of the orientation of the circuit, this finding is new and calls for further study to find the reasons behind it.

\section{Conclusions}

In this paper a benchmarking model for F1 circuits has been proposed. It involves carrying out an efficiency assessment of the circuits'designs along three key dimensions: speed, fuel consumption and safety. Efficient circuits can be identified and for the inefficient ones specific targets for improvement as well as a reference set are computed. In addition, separate speed, fuel and safety efficiency scores have been determined. CRS efficiency scores have been also computed. The results show that, in the VRS case, all but five circuits are technicallyefficient. In the CRS case four additional circuits are deemed inefficient. When considering each dimension of improvement separately then significant potential improvements have been estimated for the inefficient circuits. The inefficiencies, i.e. the margins for improvement, are highest for the safety dimension and lowest for the speed dimension. These are general remarks about the obtained results but specific figures for each inefficient circuit are provided by the proposed approach, allowing a case by case analysis of the results of each circuit.Moreover, since the proposed approach can rank the circuits based on their efficiency score and since, now and in the future, it can happen that there are more circuits than the actual number of races that can take place in a given season, the circuits' efficiency scores might be used, together with other factors, to select the circuits to be included in the F1 championship. The proposed DEA model can also be used to estimate the changes in fastest lap, fuel consumption and number of accidents to be expected as a result of a circuit redesign (e.g. removing or adding a turn).

The DEA efficiency scores have beenregressed, using a fractional regression model, to measure the influence of the circuit type, track orientation and rainfall likelihood on the 
circuit efficiency. The results of this second-stage DEA regression indicate, with a reasonable goodness of fit, that all three variables appear to significantly affect efficiency across F1 circuits, with the corresponding implications for track designers and F1 organizers.

There are, however, limitations of the study that one should be aware of. Some circuits could not be included in the analysis due to missing data on input or output variables. Also, even though the number of withdrawals due to accidents and collisions used as a measure of safety excluded the mechanical failure causes, not all the accidents and collisions may be ascribed to circuit safety issues. Thus, some accidents may have been due to driver error and not the fault of the circuit design and maintenance. This means that the computed safety efficiency may have been underestimated.

Finally, as topics for further research, we can mention the possibility of selectinga different set of variables, reflecting the perspective of some other stakeholder. Also, a network DEA approach that considered two stages in series, namely a design stage and a racing stage, each one with its corresponding inputs, outputs and intermediate measures, can also be conceived.

Acknowledgements. This research was carried out with the financial support of the Spanish Ministry of Science and the European Regional Development Fund (ERDF) grant DPI2017-85343-P. The authors are grateful to the reviewers for their helpful remarks and suggestions.

\section{References}

Alnaser, N.W., Flanagan, R., Al-Khalifa, S.E., Mumtaz, R., El-Masri, S. and Alnaser, W.E. (2007).Architectural, construction and environmental matters of Bahrain's International Formula 1 Circuit.Building and Environment 42, 1783-1794

Amin, G.R. and Sharma, S.K. (2014).Cricket team selection using data envelopment analysis.European Journal of Sport Science 14, 369-376

Anderson, A. (2014). Maximum likelihood ranking in racing sports.Applied Economics $46,1778-1787$ 
Anh Tran, N., G. Shively, and P. Preckel (2010).A New Method for Detecting Outliers in Data Envelopment Analysis.Applied Economics Letters 17 (4) 313-316

Banker, R.D and Morey, R. (1986).Efficiency analysis for exogenously fixed inputs and outputs.Operations Research 34, 513-521

Banker, R.D., Charnes, A. and Cooper, W.W. (1984). Some models for estimating technical and scale inefficiencies in Data Envelopment Analysis. Management Science 30, 1078-1092

Bell, A., Smith, J., Sabel, C.E. and Jones, K. (2016). Formula for success: Multilevel modelling of Formula One Driver and Constructor performance, 1950-2014. Journal of Quantitative Analysis in Sports 12, 99-112

Braglia, M. andPetroni, A. (1999). Evaluating and selecting investments in industrial robots. International Journal of Production Research 37, 4157-4178

Camanho, A. S., Portela, M. C. and Vaz, C. B. (2009).Efficiency analysis accounting for internal and external non-discretionary factors.Computers and Operations Research 36 (5) 1591-1601

Casanova, D., Sharp, R.S. and Symonds, P. (2001).Construction of race circuit geometry from on-car measurements.Proceedings of the Institution of Mechanical Engineers, Part D: Journal of Automobile Engineering 215, 1033-1042

Castellucci, F., Padula, M. and Pica, G. (2011). The age-productivity gradient: evidence from a sample of F1 drivers. Labour Economics 18, 464-473

Charnes, A., Cooper, W.W. and Rhodes, E. (1978). Measuring the efficiency of decision making units European Journal of Operational Research 2, 429-444

Chaves, M.C.C., Gomes Junior, S.F., Pereira, E.R. andSoares de Mello, J.C.C.B. (2010). Utilização do método ELECTRE II para avaliação de pilotos no campeonato de Fórmula 1. Produção 20 (1) 102-113

Cheng, E. and Jarvis, N. (2010).Residents' perception of the social-cultural impacts of the 2008 Formula 1 Singtel Singapore Grand Prix.Event Management 14, 91-106 
Chen, Y., Gong, Y. and Li, X, (2017). Evaluating NBA player performance using bounded integer data envelopment analysis.Informs 55, 38-51

Cooper W.W., Seiford, L.M. and Tone, K. (2006).Data Envelopment Analysis: A Comprehensive Text with Models, Applications, References and DEA-Solver Software, 2nd edition, Springer, New York

Cooper W.W., Seiford, L.M. and Zhu, J. (2004).Handbook on Data Envelopment Analysis, Springer, New York

Cook, W.D., Tone, K. and Zhu, J. (2014). Data Envelopment Analysis: Prior to choosing a model. Omega $44,1-4$

de Carlos, P., Aléna, E. and Pérez-González, A. (2017). Measuring the efficiency of the Spanish Olympic Sports Federations.European Sports Management Quarterly 17, 22102225

Demir, E., Bektaş, T. and Laporte, G. (2014). A review of recent research on green road freight transportation, European Journal of Operational Research 237 (3) 775-793

Doyle, J. and Green, R. (1991).Comparing products using data envelopment analysis.Omega 19, 6, 631-638

Ertay, T., Ruan, D. andTuzkaya, U.R. (2006).Integrating data envelopment analysis and analytic hierarchy for the facility layout design in manufacturing systems.Information Sciences $176,237-262$

Espitia-Escuer, M. andGarcía-Cebrián, I. (2010).Measurement of the Efficiency of Football Teams in the Champions League.Managerial and Decision Economics 31, 373-386

Fairley, S., Tyler, B.D., Kellet, P. andD'Elia, K. (2011). The Formula One Australian Grand Prix: exploring the triple bottom line. Sport Management Review 14, 141-152

Färe, R. andGrosskopf, S. (2003). Nonparametric Productivity Analysis with Undesirable Outputs.American Journal of Agricultural Economics 85 (4) 1070-1074 
Ferreira, D.C. and Marques, R.C. (2016).Malmquist and Hicks-Moorsteen productivity indexes for clusters performance evaluation. International Journal of Information Technology \& Decision Making 55, 1015-1053

Ferreira, D.C. and Marques, R.C. (2018). A step forward on order- $\alpha$ robust nonparametric method: Inclusion of weight restrictions, convexity, and non-variable returns to scale. Operational Research International Journal (doi: 10.1007/s12351-0170370-1)

Ferreira, D.C., Marques, R.C. and Nunes, A.M. (2018). Economies of scope in the health sector: The case of Portuguese hospitals. European Journal of Operational Research 266, 716-735

FIA, FédérationInternationale de l'Automobile (2017). (Last accessed Dec 14 2017, http://www.fia.com)

FIA, FédérationInternationale de l'Automobile (2018). (Last accessed May 06 2018, https://www.fia.com/circuit-list-requirements-circuit-drawing-0)

Formula One Management (2017).Formula One Management's 2016 Global Media Report (Last accessed May 08 2017, http:// www. fia.com)

Fukuyama, H. and Weber, W.L. (2010). A Slacks-based Inefficiency Measure for a Two-stage System with Bad Outputs.Omega 38, 239-410

Gomes Junior, S.F. andSoares de Mello, J.C.C.B. (2007).Avaliação dos pilotos no campeonato mundial de Fórmula 1 no ano de 2006 utilizando modelo DEA comrestriçõesconerationãoarquimedianas. SistemasandGestão 2, 216-230

Gutiérrez, E. and Lozano, S. (2014). A DEA approach to performance-based budgeting of Formula One constructors.Journal of Sports Economics 15, 180-200

Henry, N., Angus, T., Jenkins, M. and Aylett, C. (2007).Motorsport going global: The challenges facing the world's motorsport industry. Palgrave Macmillan.

Herrero, I. andSalmerón, J.L. (2005).Using the DEA Methodology to rank software technical efficiency.Communications of the ACM 48, 101-105 
Hoff, A. (2007). Second stage DEA: Comparison of approaches for modelling the DEA score. European Journal of Operational Research 181, 425-435

Hwang, S.N., Chen, C., Chen, Y., Lee, H.S. and Shen, P.D. (2013). Sustainable design performance evaluation with applications in the automobile industry: Focusing on inefficiency by undesirable factors. Omega $41,553-558$

Jago, L., Chalip, L., Brown, G., Mules, T. and Ali, S. (2003). Building events into destination branding.Event Management 8, 3-14

Jenkins, M. and Floyd, S. (2001). Trajectories in the evolution of technology: a multilevel study of competition in Formula 1 racing. Organization Studies 22, 945-969

Judde, C., Booth, R. and Brooks, R. (2013). Second place is first of the losers: an analysis of competitive balance in Formula One. Journal of Sports Economics 14, 411439

Klaasen, F.J.G.M. and Magnus, J.R. (2009). The efficiency of top agents: An analysis through service strategy in tennis. Journal of Econometrics 148, $72-85$

Kladroba, A. (2000). Das Aggregationsproblem bei der Erstellung von Rankings: Einige Anmerkungen am Beispiel der Formel 1 Weltmeisterschaft 1998. Jahrbucher fur Nationalokonomie und Statistik 220, 302-314

Kuosmanen, T. (2005).Weak disposability in nonparametric production analysis with undesirable outputs.American Journal of Agricultural Economics 87, 1077-1082

Lefebvre, S. andRoult, R (2011).Formula One's new urban economies.Cities 28, 330339

Lewis, H.F., Lock, K.A. and Sexton, T.R. (2009). Organizational capability, efficiency, and effectiveness in Major League Baseball: 1901-2002. European Journal of Operational Research 197, 731-740

Liu, D. andGratton, C. (2010). The impact of mega sporting events on live spectators' images of a host city: a case study of the Shanghai F1 Grand Prix. Tourism Economics $17,629-645$ 
Lozano, S. (2016).Slacks-based inefficiency approach for general networks with bad outputs.An application to the banking sector.Omega $60,73-84$

Lozano, S. and Gutiérrez, E. (2011). Slacks-based measure of efficiency of airports with airplanes delays as undesirable outputs. Computers and Operations Research 38, 131139

Lozano, S., Gutiérrez, E. and Moreno, P. (2013).Network DEA approach to airports performance assessment considering undesirable outputs.Applied Mathematical Modelling 37, 1665-1676

Lozano, S., Villa, G., Guerrero, F. and Cortés, P. (2002).Measuring the performance of nations at the Summer Olympics using data envelopment analysis.Journal of the Operational Research Society 53, 501-511

McDonald, J. (2009). Using least squares and tobit in second stage DEA efficiency analyses.European Journal of Operational Research 197(2) 792-798.

Minoyama, O. andTsuchida, H. (2004). Injuries in professional motor car racing drivers at a racing circuit between 1996 and 2000. British Journal Sports Medicine 38, 613-616

Moreno, P. and Lozano, S. (2014). A network DEA assessment of team efficiency in the NBA.Annals of Operations Research 214, 99-124

Papachristos, G. (2014). Technology, performance and team adaptation to regulation in Formula 1, 32nd International Conference of the System Dynamics Society, 20-24 July, 2014, Delft, Netherlands

Papahristodoulou, C. (1997). A DEA model to valuate car efficiency.Applied Economics 29, 1493-1508

Papke, L.E. and Wooldridge, J.M. (1996). Econometric methods for fractional response variables with an application to 401(k) plan participation rates. 1996. Journal of Applied Econometrics, 11(6) 619-632

Pastor, J.T. andAparicio, J., (2010).A note on "A directional slacks-based measure of technical inefficiency”.Socio-Economic Planning Sciences 44, 174-175 
Pastor, J.T., Aparicio, J., Alcaraz, J., Vidal, F. and Pastor, D. (2016).The Reverse Directional Distance Function, in Advances in Efficiency and Productivity, J. Aparicio et al. (eds.), International Series in Operations Research \& Management Science, vol. $249,15-55$

Perantoni, G. and Limebeer, D.J.N. (2014). Optimal control for a Formula One car with variable parameters.Vehicle System Dynamics 52, 653-678

Pfahl, M.E. and Bates, B.R. (2008). This is not a race, this is a farce: Formula One and the Indianapolis Motor Speedway tire crisis. Public Relations Review 34, 135-144

Phillips, A.J.K. (2014). Uncovering Formula One driver performances from 1950 to 2013 by adjusting for team and competition effects.Journal of Quantitative Analysis in Sports 10, 261-218

Ramalho, E.A., Ramalho, J.J.S. andHenriques, P.D. (2010). Fractional regression models for second stage DEA efficiency analyses.Journal of Productivity Analysis, 34, 239-255

Ramalho, J.J.S. (2017). frm: Regression Analysis of Fractional Responses. R package, version 3.4.0.(downloadable from http://CRAN.R-project.org/package=frm)

Ramsey, J.B. (1969). Tests for Specification Errors in Classical Linear Least Squares Regression Analysis.Journal of the Royal Statistical Society Series B 31 (2) 350-371

Rosenberger, P.J. and Donahay, B. (2008). Brand personality differentiation in formula one motor racing: An Australian view. Marketing Bulletin 19, Article 2, 1-14

Ruiz, J.L., Pastor, D. and Pastor, T. Assessing Professional (2013). Tennis Players Using Data Envelopment Analysis (DEA).Journal Sports of Economics 14, 276-302

Savage, G. (2010). Dealing with crisis-solving engineering failures in Formula 1 motor racing.Engineering Failure Analysis 17, 760-770

Scheel, H. (2001). Undesirable outputs in efficiency valuations.European Journal of Operational Research 132 (2) 400-410. 
Seiford, L.M. and Zhu, J. (2002).Modeling undesirable factors in efficiency evaluation.European Journal of Operational Research 142 (1) 16-20

Simar, L. and Wilson, P.W. (2008). Statistical Inference in Nonparametric Frontier Models: Recent Developments and Perspectives. In The Measurement of Productive Efficiency and Productivity Growth, edited by F.O. Fried, C.A.K. Lovell and S.S.Schmidt, 757-930. Oxford: Oxford University Press

Sitarz, S. (2013).The medal points' incenter for rankings in sport.Applied Mathematics Letters 26, 408-412

Soares de Mello, J.C.C.B., Gomes Junior, S.F. Angulo Meza, L. andMourão, C.L.O. (2015). Condorcet method with weakly rational decision makers: a case study in the Formula 1 constructors Championship. Procedia Computer Science 55, 493-502

Solitander, M. andSolitander, N. (2010). The sharing, protection and thievery of intellectual assets: The case of the Formula 1 industry. Management Decision 48, 37-57

Tone, K. (2001). A slacks-based measure of super-efficiency in data envelopment analysis.European Journal of Operational Research 143, 32-41

Villa, G. and Lozano, S. (2016).Assessing the scoring efficiency of a football match.European Journal of Operational Research 255, 559-569

Wang, K., Xian, Y., Lee, C.Y., Wei, Y.M. and Huang, Z. (2017). On selecting directions for directional distance functions in a non-parametric framework: a review.Annals of Operations Research, (doi: 10.1007/s10479-017-2423-5)

Wloch, K. and Bentley, P.J. (2004).Optimising the Performance of a Formula One Car Using a Genetic Algorithm,Lecture Notes in Computer Science book series (LNCS, volume 3242), 702-711

Wu, J., Zhou, Z. and Liang, L. (2010). Measuring the performance of nations at Beijing Summer Olympics using integer-valued DEA model.Journal of Sports Economics 11, 549-566

Xue, H. and Mason, D.S. (2011).The changing stakeholder map of Formula One Grand Prix in Shanghai.European Sport Management Quarterly 11, 371-395 


\section{List of figures and table captions}

Figure 1. DEA inputs and outputs considered

Figure 2. Boxplots of inputs and output variables

Figure 3. Scatterplots of input and output variables

Figure 4. Variable-specific directional distance function along safety, fuel and speed dimensions

Table 1. Dataset of auto racing circuits in Formula One motor racing series $(N=21)$

Table 2. Number of car withdrawals from the race due to accident/collision causes during the period 1998-2014

Table 3. Efficiency scores and potential improvements

Table 4. Reference set and optimal values of of $\lambda_{j}$ and $\mu_{j}$ variables

Table 5. Regression models estimates 


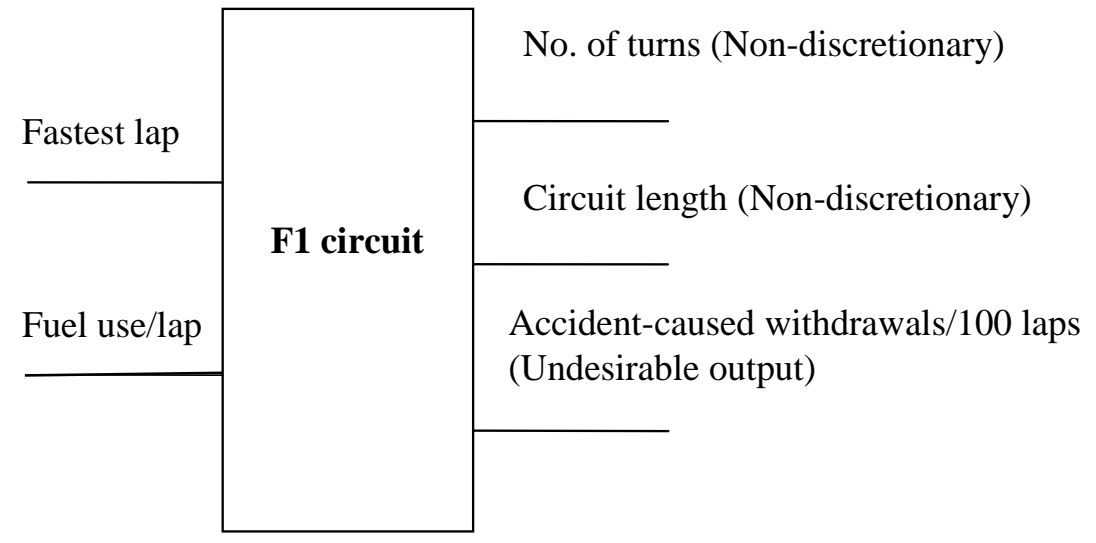

Figure 1. DEA inputs and outputs considered 

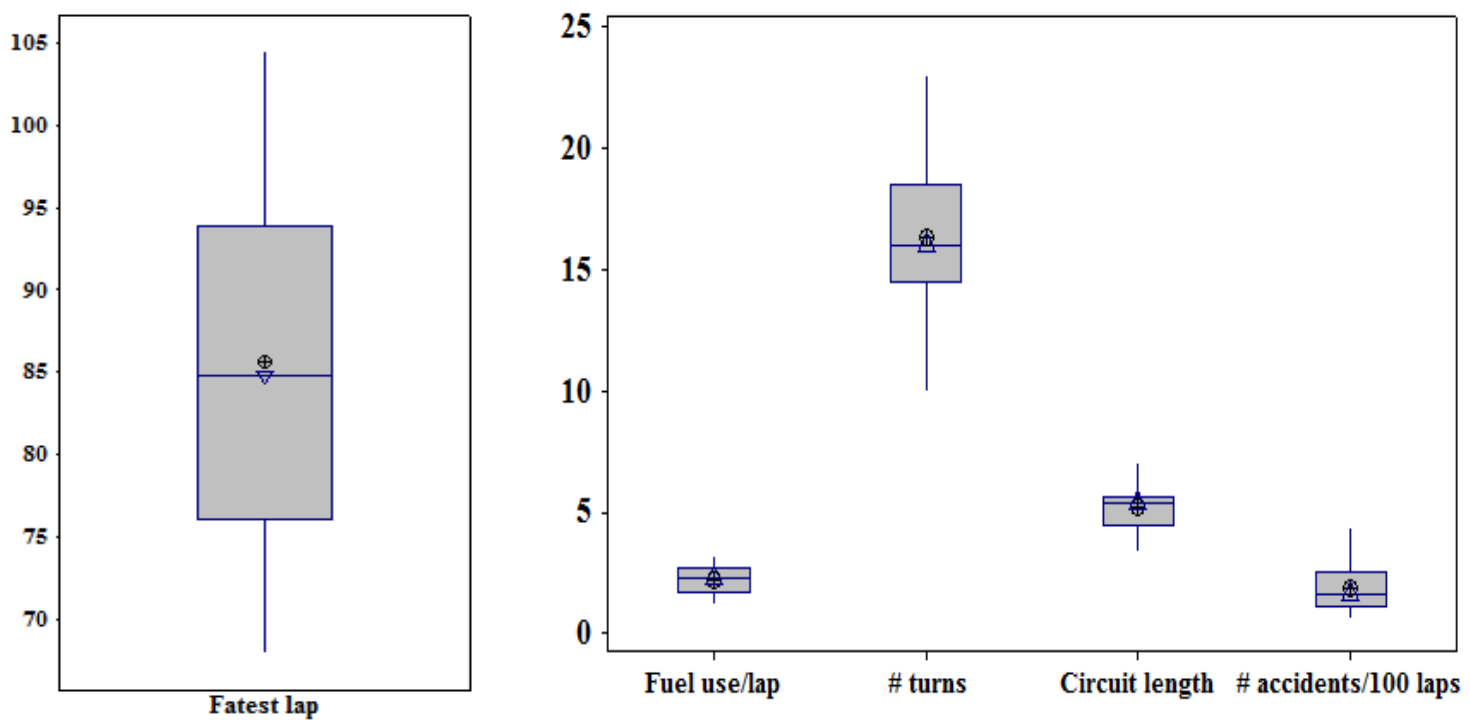

Figure 2. Boxplots of inputs and output variables 


\section{Fastest lap}

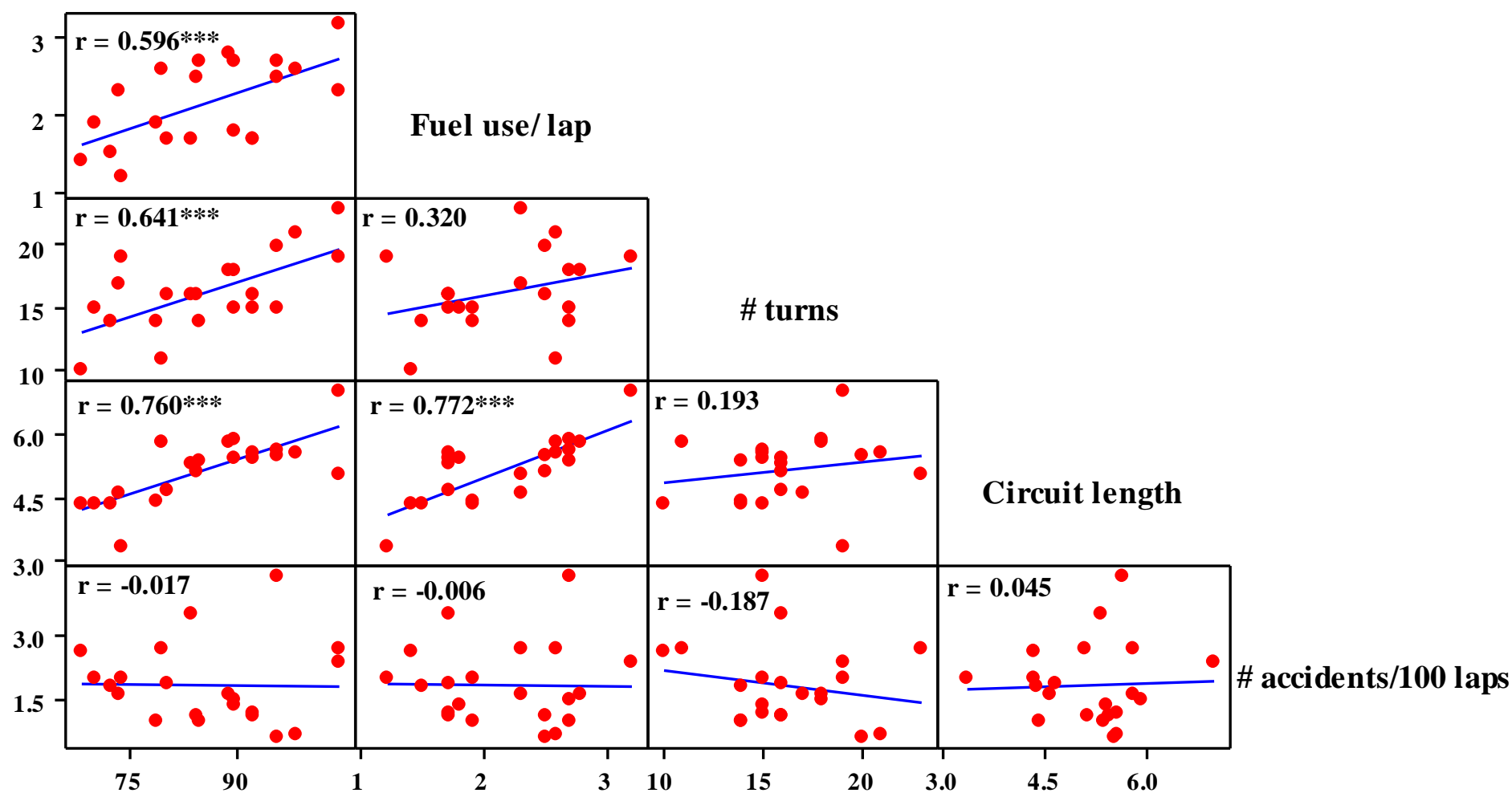

Note: "r" indicates the Pearson correlation coefficient. “***" indicates statistical significance at the $1 \%$ levels.

Figure 3. Scatterplots of input and output variables 


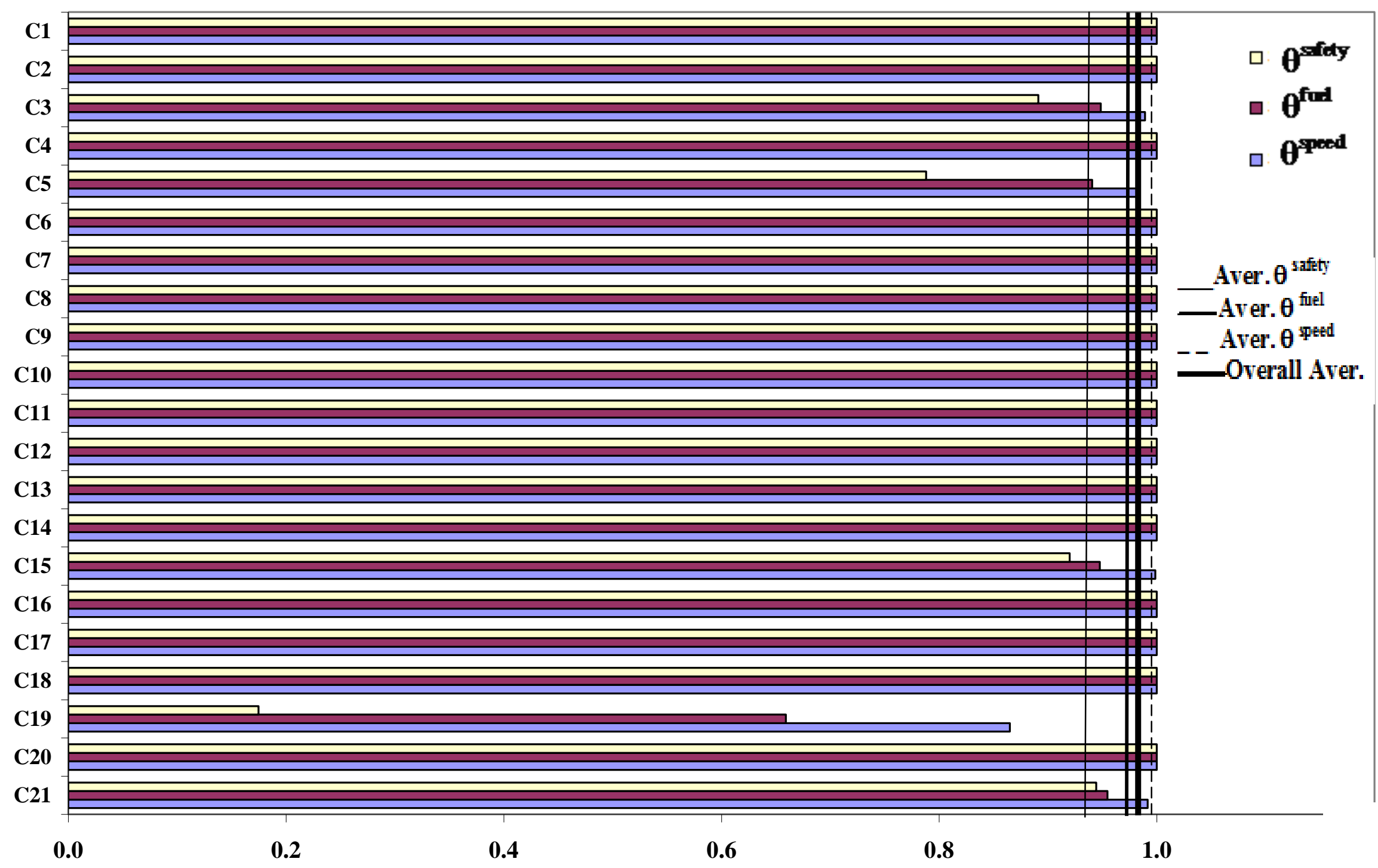

Figure 4. Variable-specific directional distance function along safety, fuel and speed dimensions 
Table 1. Dataset of auto racing circuits in Formula One motor racing series $(N=21)$

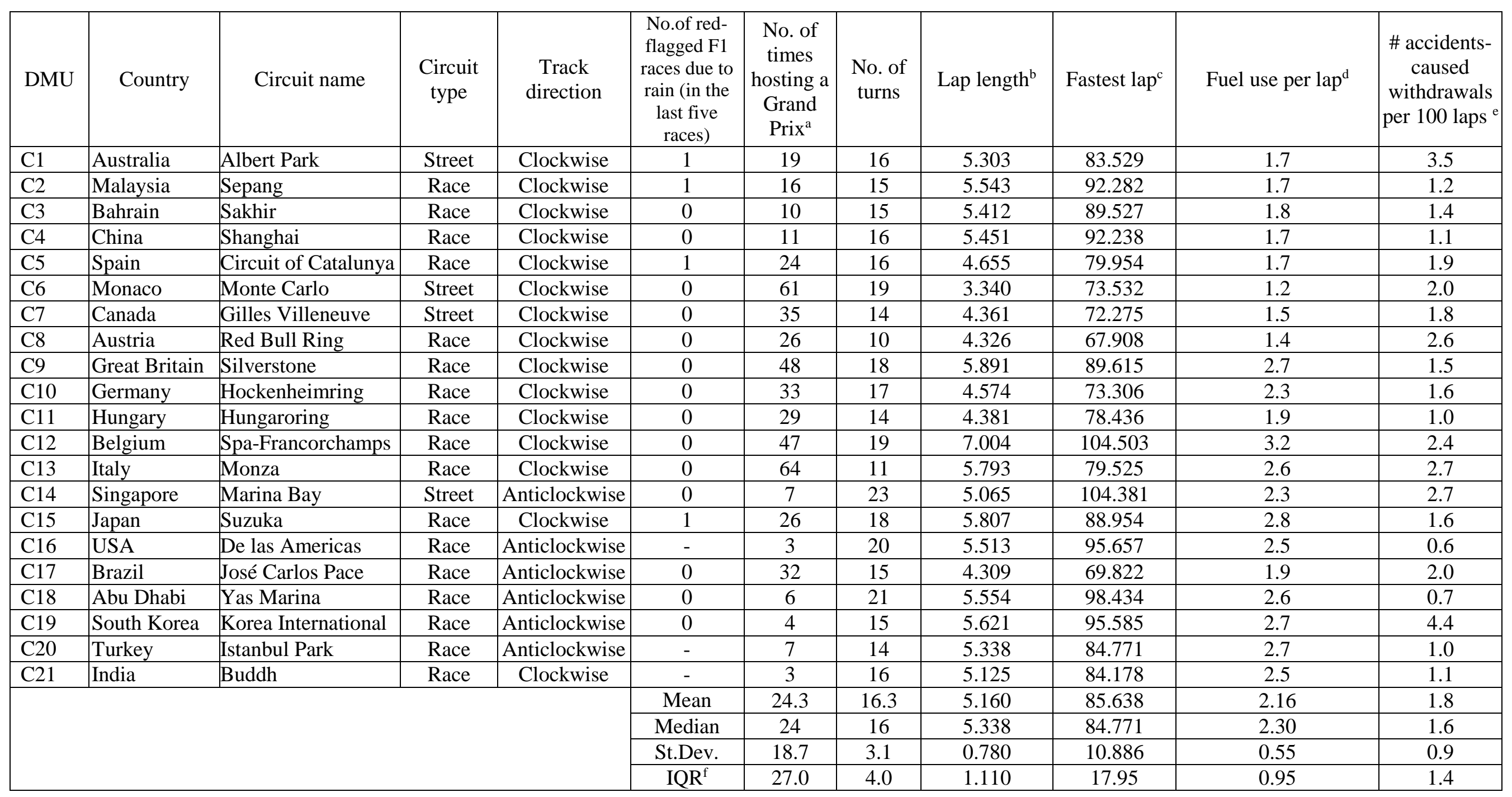

Sources: http: //www. fia.com; http://en.espnf1.com/; http://f1-facts.comไresults (last accessed December, 2017).

Notes: ${ }^{\text {afrom }} 1950$ till 2014; ${ }^{\mathrm{b}}$ in kilometres; ${ }^{\mathrm{c}}$ in seconds; ${ }^{\mathrm{d}}$ in kilograms; ${ }^{\mathrm{e}}$ covers the period 1998-2014 and excludes mechanical failure causes; ${ }^{\mathrm{f}}$ Interquartile range 
Table 2. Number of car withdrawals from the race due to accident/collision causes during the period 1998-2014

\begin{tabular}{|c|c|c|c|c|c|c|c|c|c|c|c|c|c|c|c|c|c|c|}
\hline Circuit & Circuit name & 201 & 2013 & 2012 & 2011 & 2010 & 2009 & 2008 & 2007 & 2006 & 2005 & 2004 & 2003 & 2002 & 2001 & 2000 & 1999 & 1998 \\
\hline $\mathrm{C} 1$ & Albert Park & 1 & 0 & 0 & 1 & 3 & 1 & 8 & 2 & 3 & 2 & 0 & 0 & 8 & 2 & 0 & 3 & 1 \\
\hline $\mathrm{C} 2$ & Sepang & 1 & 0 & 0 & 1 & 0 & 0 & 1 & 1 & 1 & 2 & 0 & 0 & 0 & 0 & 3 & 1 & \\
\hline $\mathrm{C} 3$ & Sakhir & 3 & 0 & 0 & & 1 & 0 & 2 & 2 & 0 & 0 & 0 & & & & & & \\
\hline $\mathrm{C} 4$ & \begin{tabular}{|l|} 
Shanghai \\
\end{tabular} & 0 & 0 & 0 & 0 & 3 & 1 & 1 & 0 & 1 & 0 & 1 & & & & & & \\
\hline $\mathrm{C} 5$ & Circuit of Catalunya & 0 & 0 & 0 & 1 & 0 & 4 & 5 & 1 & 0 & 0 & 0 & 4 & 0 & 2 & 2 & 0 & 2 \\
\hline C6 & Monte Carlo & 1 & 0 & 4 & 3 & 3 & 2 & 2 & 0 & 0 & 1 & 5 & 0 & 3 & 1 & 0 & 1 & 1 \\
\hline $\mathrm{C} 7$ & Gilles Villeneuve & 2 & 0 & 0 & 3 & 0 & & 3 & 1 & 2 & 0 & 1 & 1 & 0 & 3 & 1 & 2 & 2 \\
\hline $\mathrm{C} 8$ & Red Bull Ring & 0 & & & & & & & & & & & 0 & 3 & 0 & 5 & 0 & 5 \\
\hline C9 & \begin{tabular}{|l|} 
Silverstone \\
\end{tabular} & 3 & 0 & 1 & 0 & 1 & 2 & 0 & 1 & 3 & 0 & & 0 & 0 & 2 & 0 & 0 & 0 \\
\hline $\mathrm{C} 10$ & Nürburgring & 1 & & 0 & & 0 & 0 & 1 & 0 & 0 & 0 & 0 & 5 & 0 & 3 & 4 & 2 & 0 \\
\hline $\mathrm{C} 11$ & Hungaroring & 4 & 0 & 0 & 0 & 0 & 0 & 0 & 1 & 2 & 2 & 0 & 1 & 0 & 0 & 0 & 0 & 0 \\
\hline $\mathrm{C} 12$ & Spa-Francorchamps & 0 & 1 & 5 & 0 & 3 & 4 & 0 & 0 & & 3 & 5 & & 0 & 0 & 1 & 0 & 5 \\
\hline $\mathrm{C} 13$ & Monza & 0 & 1 & 0 & 4 & 0 & 1 & 1 & 1 & 0 & 0 & 1 & 0 & 2 & 1 & 5 & 3 & 0 \\
\hline $\mathrm{C} 14$ & Marina Bay & 0 & 0 & 2 & 2 & 5 & 1 & 0 & & & & & & & & & & \\
\hline $\mathrm{C} 15$ & Suzuka & 2 & 2 & 1 & 0 & 4 & 0 & 1 & 0 & 0 & 1 & 2 & 0 & 0 & 1 & 0 & & 2 \\
\hline $\mathrm{C} 16$ & De las Americas & 0 & 1 & 0 & & & & & & & & & & & & & & \\
\hline $\mathrm{C} 17$ & José Carlos Pace & 0 & 1 & 0 & 0 & 0 & 4 & 1 & 2 & 1 & 2 & 1 & 0 & 1 & 1 & 3 & 2 & 0 \\
\hline $\mathrm{C} 18$ & Yas Marina & 0 & 0 & 3 & 0 & 0 & 0 & & & & & & & & & & & \\
\hline $\mathrm{C} 19$ & Korea International & 0 & 0 & 2 & 0 & 10 & & & & & & & & & & & & \\
\hline $\mathrm{C} 20$ & Istanbul Park & & & & 0 & 1 & 0 & 2 & 0 & 1 & 0 & & & & & & & \\
\hline $\mathrm{C} 21$ & Buddh & & 1 & 0 & 1 & & & & & & & & & & & & & \\
\hline
\end{tabular}


Source: http://en.espnf1.com/ 
Table 3. Efficiency scores and potential improvements

\begin{tabular}{|c|c|c|c|c|c|}
\hline \multirow{3}{*}{ Circuit } & \multicolumn{4}{|c|}{ VRS } & \multirow{3}{*}{$\begin{array}{c}\text { CRS } \\
\begin{array}{c}\text { Efficiency } \\
\text { score }\end{array}\end{array}$} \\
\hline & \multirow{2}{*}{$\begin{array}{l}\text { Efficiency } \\
\text { score }\end{array}$} & \multicolumn{3}{|c|}{ Potential reductions } & \\
\hline & & Fastest lap & Fuel use/km & $\#$ accidents/100 laps & \\
\hline $\mathrm{C} 1$ & 1.000 & - & - & - & 1.000 \\
\hline $\mathrm{C} 2$ & 1.000 & - & - & - & 1.000 \\
\hline $\mathrm{C} 3$ & 0.963 & 0.0 & 0.0 & 0.1 & 0.938 \\
\hline $\mathrm{C} 4$ & 1.000 & - & - & - & 1.000 \\
\hline $\mathrm{C} 5$ & 0.929 & 0.000 & 0.0 & 0.4 & 0.920 \\
\hline C6 & 1.000 & - & - & - & 1.000 \\
\hline $\mathrm{C} 7$ & 1.000 & - & - & - & 1.000 \\
\hline $\mathrm{C} 8$ & 1.000 & - & - & - & 1.000 \\
\hline C9 & 1.000 & - & - & - & 1.000 \\
\hline $\mathrm{C} 10$ & 1.000 & - & - & - & 1.000 \\
\hline $\mathrm{C} 11$ & 1.000 & - & - & - & 0.833 \\
\hline $\mathrm{C} 12$ & 1.000 & - & - & - & 0.954 \\
\hline $\mathrm{C} 13$ & 1.000 & - & - & - & 1.000 \\
\hline $\mathrm{C} 14$ & 1.000 & - & - & - & 0.820 \\
\hline $\mathrm{C} 15$ & 0.958 & 0.000 & 0.1 & 0.1 & 0.957 \\
\hline $\mathrm{C} 16$ & 1.000 & - & - & - & 1.000 \\
\hline $\mathrm{C} 17$ & 1.000 & - & - & - & 0.921 \\
\hline $\mathrm{C} 18$ & 1.000 & - & - & - & 1.000 \\
\hline C19 & 0.640 & 2.651 & 0.9 & 3.1 & 0.631 \\
\hline $\mathrm{C} 20$ & 1.000 & - & - & - & 1.000 \\
\hline $\mathrm{C} 21$ & 0.981 & 0.000 & 0.0 & 0.1 & 0.909 \\
\hline
\end{tabular}


Table 4. Reference set and optimal values of of $\lambda_{j}$ and $\mu_{j}$ variables

\begin{tabular}{|c|c|}
\hline Circuit & Reference Set $\left(\lambda_{\mathrm{j}}, \mu_{\mathrm{j}}\right)$ \\
\hline $\mathrm{C} 3$ & $\begin{array}{l}\text { C2 }(0.802,0.0) \\
\text { C7 }(0.120,0.0) \\
\text { C9 }(0.050,0.0) \\
\text { C20 }(0.028,0.0)\end{array}$ \\
\hline C5 & $\begin{array}{l}\text { C4 }(0.225,0.0) \\
\text { C6 }(0.112,0.0) \\
\text { C7 }(0.459,0.0) \\
\text { C10 }(0.077,0.0) \\
\text { C16 }(0.127,0.0)\end{array}$ \\
\hline $\mathrm{C} 15$ & $\begin{array}{l}\text { C9 }(0.909,0.0) \\
\text { C10 }(0.052,0.0) \\
\text { C16 }(0.035,0.0) \\
\text { C20 }(0.004,0.0)\end{array}$ \\
\hline C19 & $\begin{array}{l}\text { C2 }(0.947,0.0) \\
\text { C12 }(0.053,0.0)\end{array}$ \\
\hline $\mathrm{C} 21$ & $\begin{array}{l}\mathrm{C} 10(0.215,0.0) \\
\mathrm{C} 11(0.092,0.0) \\
\mathrm{C} 16(0.226,0.0) \\
\mathrm{C} 20(0.467,0.0)\end{array}$ \\
\hline
\end{tabular}


Table 5. Regression models estimates

\begin{tabular}{|c|c|c|c|c|c|}
\hline & \multirow{2}{*}{$\begin{array}{c}\text { Ordinary Least } \\
\text { Squares }\end{array}$} & \multicolumn{4}{|c|}{ Fractional regression model ${ }^{c}$} \\
\hline & & $\operatorname{logit}$ & probit & $\log \log$ & cloglog \\
\hline Model intercept & $\begin{array}{c}0.960 * * * \\
(0.046)\end{array}$ & $\begin{array}{c}22.576 * * * \\
(0.779)\end{array}$ & $\begin{array}{c}6.407 * * * \\
(0.387)\end{array}$ & $\begin{array}{c}22.520 * * * \\
(0.776)\end{array}$ & $\begin{array}{c}3.284 * * * \\
(0.245)\end{array}$ \\
\hline Circuit type $^{\mathrm{a}}$ & $\begin{array}{l}-0.036 \\
(0.039)\end{array}$ & $\begin{array}{c}-18.263 * * * \\
(0.468)\end{array}$ & $\begin{array}{c}-4.366 * * * \\
(0.247)\end{array}$ & $\begin{array}{c}-18.152 * * * \\
(0.456)\end{array}$ & $\begin{array}{c}-2.020 * * * \\
(0.148)\end{array}$ \\
\hline $\begin{array}{c}\text { Track } \\
\text { orientation }^{\mathrm{b}}\end{array}$ & $\begin{array}{c}0.084 \\
(0.039)\end{array}$ & $\begin{array}{c}2.334 * * * \\
(0.477)\end{array}$ & $\begin{array}{c}1.087 * * * \\
(0.324)\end{array}$ & $\begin{array}{l}2.181 * * \\
(0.437)\end{array}$ & $\begin{array}{l}0.690 * * \\
(0.351)\end{array}$ \\
\hline $\begin{array}{l}\text { Number of red- } \\
\text { flagged races due } \\
\text { to rain }\end{array}$ & $\begin{array}{c}-0.093 * * \\
(0.036)\end{array}$ & $\begin{array}{c}-3.622 * * * \\
(0.134)\end{array}$ & $\begin{array}{c}-1.514 * * \\
(0.512)\end{array}$ & $\begin{array}{c}-3.487 * * * \\
(1.091)\end{array}$ & $\begin{array}{c}-0.927 * * \\
(0.398)\end{array}$ \\
\hline $\begin{array}{c}\% \text { of fitted values } \\
\text { out the range } \\
{[0,1]}\end{array}$ & $55.55 \%$ & - & - & - & - \\
\hline $\mathrm{R}^{2}$ & 0.451 & 0.963 & 0.947 & 0.964 & 0.900 \\
\hline $\begin{array}{c}\text { Sum of Squared } \\
\text { Residuals }\end{array}$ & 0.067 & 0.005 & 0.009 & 0.004 & 0.020 \\
\hline
\end{tabular}

Notes: Dependent variable: WSBM efficiency scores. Sample: 18 F1 circuit cases.

"**, "**” and "***" indicate statistical significance at the $10 \%, 5 \%$ and $1 \%$ level, respectively.

Corresponding robust standard error is reported within parentheses.

aDummy variable coded one for circuits with race tracks and zero for street racing circuits.

${ }^{b}$ Dummy variable coded one for clockwise-oriented circuits and zero for anticlockwise-oriented circuits.

'Standard one-part fractional regression model. Quasi-maximum likelihood estimation method. 